\title{
Relato de experiência do Grupo de Estudos Michel Foucault*
}

\author{
Kleber Prado Filho ${ }^{I}$ \\ Simone Martins ${ }^{2}$ \\ Rodrigo Diaz de Vivar y Soler \\ Universidade Federal de Santa Catarina
}

$\mathrm{O}$ artigo relata as experiências do Grupo de Estudos Michel Foucault entre os anos de 2005 e 2009, em termos do desenvolvimento de programas de leitura e discussão de textos. O Grupo é uma atividade de extensão do Departamento de Psicologia da UFSC, sob coordenação de um professor da referida unidade. Seus objetivos mais gerais ligam-se à divulgação do pensamento foucaultiano, servindo de suporte a atividades de pesquisas acadêmicas de mestrado e doutorado, buscando não apenas a aplicação, como o desenvolvimento e atualização das problematizações do autor. Ao longo do período relatado foram desenvolvidos oito programas de estudos, organizados por temáticas levantadas pelo Grupo, além da conclusão e defesa de dez dissertações de mestrado e três teses de doutorado. Nesse intervalo, integrantes do Grupo produziram em parceria diversos artigos e capítulos de livros, além de palestras, mesas redondas e apresentações de trabalhos em congressos.

Palavras-chave: Michel Foucault - Grupo de estudos - Relato de experiência.
The article gives a narrative of experiences of Michel Foucault Study Group between 2005 and 2009 in terms of developing programs for reading and discussion of texts. The Group is an outreach activity of the Psychology Department at UFSC, coordinated by a teacher of the unit. His more general objectives link to the publication of Foucault's thought, supporting the activities of academic research master's and doctorate, seeking not only the application, such as developing and updating the problematization of the author. It is noteworthy that during the reporting period were developed eight programs of study, organized according to themes raised by the Group, in addition to the completion and defense of ten master's theses and three Ph.D. theses. In this interval in the Group have jointly produced several articles and book chapters, and lectures, round tables and presentations of works in various conferences.

Keywords: Michel Foucault - Group studies-Experience report.

\footnotetext{
* Narrative of experiences of Michel Foucault Study Group

${ }^{1}$ Doutor em Sociologia pela USP, Professor Associado do Departamento de Psicologia da UFSC e Coordenador do Grupo de Estudos Michel Foucault. Endereço para correspondências: Caixa Postal 5068, Florianópolis, SC, 88040-970 (kleberprado.psi@gmail.com).

${ }^{2}$ Mestre em Psicologia pela UFSC e Monitora do Grupo de Estudos Michel Foucault 2005-07 (smartins27@yahoo.com.br).

${ }^{3}$ Mestre e Doutorando em Psicologia pela UFSC, Professor do Centro Universitário Catarinense e Monitor do Grupo de Estudos Michel Foucault 2007-09 (diazsoler@gmail.com).
} 


\section{HUMANAS}

\section{Porque estudar Foucault?}

$\mathrm{O}$ filósofo francês Michel Foucault foi com certeza um dos personagens mais marcantes no cenário cultural e intelectual da segunda metade do século XX, para muito além da Europa e talvez do seu próprio tempo. Nascido em 1926 e falecido em 1984, produziu não apenas livros conhecidos, mas grande volume de textos de variados formatos - seus "ditos e escritos" - incluindo, artigos, entrevistas, palestras, seminários, aulas, e ainda, manifestos políticos, aberturas de exposições de arte e homenagens póstumas, em diversas línguas e países. Merece destaque em meio a essa farta produção intelectual a publicação integral dos seus cursos ministrados no Collège de France entre 1970 e 1982, organizada contemporaneamente por leitores de peso, iniciativa que atualiza seu pensamento.

Seus trabalhos têm repercussão em diversos campos de conhecimento: ele é da maior importância para a filosofia nos termos da sua crítica à modernidade, podendo ser inscrito na corrosiva tradição da desconstrução nietzschiana, que no início do século XX passa por Heiddegger e por alguns contemporâneos seus, como Deleuze, Guattari e Derrida, mais ao final do período. Muitas vezes apontado como "estruturalista" ou "pós-estruturalista" resiste a todas as nomeações e categorizações disciplinarizantes, trabalhando no registro das descontinuidades, exercitando um pensamento orientado para a questão política da diferença.

Ele é também da maior importância nos domínios das ciências humanas e sociais - para a história, a sociologia, a ciência política, a antropologia, a demografia, a psicologia e a psicanálise - tanto em termos temáticos quanto metodológicos. Seus trabalhos exercem uma influência marcante no campo da história, particularmente a partir da polêmica levantada com a especialidade da história das idéias e do conhecimento na Introdução de $A$ arqueologia do saber, onde ele coloca em questão alguns pilares do trabalho do historiador tradicional. Na tradição de Niestzsche, o pensamento foucaultiano é radicalmente histórico, levantando suspeitas sobre todas as formas de naturalidade e essencialismo operantes no discurso moderno, criticando certa tendência a um "retorno às origens" ${ }^{5}$ habitual entre os historiadores. Isso não é mera posição teórica à medida que produz efeitos políticos bem concretos expondo naturalizações estrategicamente produzidas para sustentar nossas verdades e certezas cotidianas.

\footnotetext{
4 Título de uma coletânea de textos publicada por Daniel Defert, François Ewald e Jacques Lagrange em 1994, após a sua morte, reunindo 364 trabalhos, num volume de aproximadamente 3.500 páginas, material que ainda está sendo traduzido para o português e publicado entre nós.

5 Referência a uma das faces do "quadrilátero antropológico" no qual se encontra tautologicamente encerrado o pensamento moderno, tal como trabalhado no capitulo IX do livro As palavras e as coisas, intitulado $O$ homem e seus duplos.
} 


\section{Relato de experiência do Grupo de Estudos Michel Foucault}

K. Prado Filho, S. Martins \& R.D. de Vivar y Soler

Derivam daí seus métodos históricos, a serem utilizados como ferramentas críticas:

- A arqueologia do saber, proposta em termos de análise histórica do discurso como prática, como regime político de produção de verdades; - A genealogia do poder proposta nos termos de uma analítica ascendente do poder, atenta a seus movimentos, fluxos e relações capilares, em suas articulações com jogos de saber e verdade;

- A genealogia da ética colocada como análise das formas históricas de relação do sujeito consigo mesmo em nossa cultura, análise dos modos históricos de subjetivação nos quais alguém se reconhece como sujeito de um preceito, norma ou valor assujeitando-se, estetizando-se e trabalhando-se com vistas a ele.

É bom destacar que nesses métodos o sujeito ocupa sempre lugar acessório: nunca opera no centro da relação de conhecimento como sujeito cognoscente, descobridor ou produtor de verdades, mas figura como efeito de saber, resultado de jogos de enunciação, que envolvem práticas de objetivação e subjetivação dos sujeitos pelos discursos.

Transbordando os domínios das ciências humanas e sociais, suas análises têm ainda desdobramentos críticos em campos de conhecimento muito diversos, como a medicina, a psiquiatria, a biologia, o direito, a criminologia, a economia, a educação, as ciências da linguagem, também as artes, não apenas a literatura, mas a estética e as artes plásticas.

Para além das fronteiras disciplinares do conhecimento - que ele não reconhece - destacam-se a riqueza, a relevância e a premência de temáticas desenvolvidas em problematizações ${ }^{6}$ diversas, sempre de forma singularmente crítica:

- Tematização do sujeito deslocada do tradicional eixo de análises da filosofia moderna;

- Tratamento da autoria, descentrado da unidade reconhecida entre autor e obra;

- Problematização da subjetividade como efeito e resultado de relações de saber-poder;

- Tematização do poder como relação e como rede microfísica, deslocando-se dos eixos de análises da teoria política tradicional para ocuparse da capilaridade e multiplicidade de poderes circulantes;

- Abordagem da formação histórica das biopolíticas como estratégias de governo e condução da vida e da saúde dos indivíduos e das populações, tecnologia fundamental à governamentalidade contemporânea;

\footnotetext{
${ }^{6} \mathrm{O}$ conceito de problematização é um operador metodológico nas análises foucaultianas, colocando em questão como e porque algo emerge em determinado momento como problema a ser enfrentado numa sociedade tanto em termos teóricos quanto práticos 


\section{HUMANAS}

- Tematização da vigilância como prática de governo fino e subjetivante das condutas dos indivíduos, também questão da maior importância para as nossas sociedades, que multiplicam a vigilância eletrônica em espaços abertos e fechados;

- Tratamento da norma como modalidade de poder tipicamente moderna, que compara e classifica indivíduos conforme critérios cientificamente definidos remetendo cada um deles a uma faixa de normalidade arbitrada, sancionando ou reprovando seus comportamentos e características particulares, o que remete ao problema política da normalização das suas condutas; - Abordagem da questão da criminalidade descentrada da relação "natural" reconhecida entre crime e criminoso, colocando em questão a "produção da delinquência" nas sociedades ocidentais;

- Problematização da sexualidade recusando sua naturalidade biológica e deslocando-se da moderna temática do sujeito do desejo.

Exploramos particularmente no grupo os desdobramentos metodológicos das suas análises nos domínios das ciências humanas e sociais, em termos da proposição de um olhar histórico-crítico atendo às rupturas e descontinuidades históricas, centrado em acontecimentos e voltado para uma análise dos jogos de verdade e enunciação, de relações de força e jogos de poder, que dá visibilidade, em última instância, aos efeitos de subjetividade resultantes destas práticas de saber-poder. Nesse sentido o pensamento foucaultiano serve não apenas como ferramenta metodológica para o estudo de fenômenos a partir dessa perspectiva, como também possibilita uma crítica daquilo que somos, instrumentalizando a resistência micropolítica aos modos de objetivação e subjetivação característicos de nossas sociedades.

Isso aponta para o problema da atualidade do seu pensamento posta em termos da sua aplicabilidade às questões do nosso tempo, que coloca a pergunta: Foucault ainda poderia ser considerado um pensador atual? Por tudo que apresentamos anteriormente entendemos que sim: pela sua importância para o pensamento moderno, para as ciências humanas e para outros tantos campos de conhecimento, pela premência temática, pulsante, também pela perspectiva crítica do nosso mundo e daquilo que somos, o que aponta para o seu projeto mais estratégico que seria o de produzir uma história do nosso presente. Assim, entendemos ser fundamental aprofundar em desdobramentos atuais do pensamento do autor, o que justifica nossa atividade.

\section{Apresentação do grupo}

O Grupo de Estudos Michel Foucault formou-se em agosto de 2005 com o objetivo de aprofundar e atualizar a leitura dos textos do autor, 


\section{Relato de experiência do Grupo de Estudos Michel Foucault}

K. Prado Filho, S. Martins \& R.D. de Vivar y Soler

visando oferecer suporte teórico-metodológico a atividades de orientação e pesquisa, além de pretender uma divulgação mais ampla do seu pensamento. Ele conta com uma composição variável conforme cada atividade proposta, sendo desenvolvido desde então como projeto de extensão vinculado ao Departamento de Psicologia da Universidade Federal de Santa Catarina (UFSC), sob coordenação de um professor da mesma unidade. No entanto, a participação nas atividades do Grupo é aberta ao público em geral - não apenas acadêmico ou universitário - não restrito aos âmbitos da psicologia, das ciências humanas, ou mesmo da pós-graduação. Em alguns momentos, quando houve confluência de interesses, o funcionamento do Grupo esteve vinculado a atividades de pesquisa, orientação e pós-graduação, embora não seja esse seu objetivo maior. Desde a sua formação em 2005 foram desenvolvidas oito atividades de estudo relativas a temas recolhidos entre os trabalhos de Foucault, conforme histórico e descrição aqui apresentados.

\section{Metodologia de trabalho}

O Grupo de Estudos M. Foucault se organiza por agenciamento de interesses temáticos em relação ao pensamento do autor, funcionando de forma consultiva, participativa e autogestionária. Existe uma lista de discussão na Internet com 48 participantes (endereço: br.groups.yahoo.com/group/Foucaultufsc/) onde é feita, pelo menos uma vez por ano, uma chamada para comparecimento de interessados na leitura do autor, em determinada data, horário e local. Nessa reunião, ouvidas as demandas individuais, traça-se um plano coletivo de estudos buscando atender aos interesses dos presentes, selecionando temas e textos a serem explorados, montando ainda um cronograma para realização de encontros temáticos quinzenais ao longo do semestre ou do ano, que é divulgado na lista do Grupo na Internet. Cada atividade é registrada no site de Extensão da UFSC, que emite certificado de participação, sendo coordenada pelo professor responsável pelo projeto. Devido ao modo de funcionamento flexível do Grupo, que em alguns momentos decidiu alterar o trajeto durante o desenvolvimento da atividade, às vezes há diferenças entre a proposta registrada e aquilo que realmente aconteceu - esse relato trata daquilo que foi efetivamente realizado.

Visando precisão metodológica esclarecemos que no item "Textos discutidos" de cada atividade relatada informamos apenas o título do texto a ser lido (quando é de Foucault), seguido do nome do autor (quando não se trata de trabalho dele) e a referência completa é citada ao final do artigo, atendendo ao padrão editorial da revista. 


\section{HUMANAS}

\section{Histórico e descrição das atividades}

Atividade - Diálogos com Foucault I

Tema examinado: Problematização da subjetividade a partir da perspectiva genealógica.

Estratégia adotada: partir do eixo metodológico saber-poder-subjetividade para compreender a crítica genealógica aos regimes modernos de produção de corpos e subjetividades.

Percurso temático: emergência do biopoder; formação da sociedade disciplinar; disciplinarização dos corpos; poder da norma e práticas de normalização; práticas de individualização e identificação; objetivação e subjetivação do indivíduo moderno; formação de dispositivos de identificação; psicologização do poder na segunda metade do século XX

Textos discutidos: A ordem do discurso; Vigiar e punir; Eu, Pierre Rivière que degolei minha mãe, minha irmã e meu irmão; O sujeito e o poder.

Procedimentos adotados: devido à complexidade do tema e ao caráter inicial dos estudos, o coordenador atuou de forma mais diretiva, fazendo apresentações dialogadas, explorando um trajeto biobibliográfico e metodológico de entrada no pensamento de Foucault.

Período de realização: 02/08/2005 a 26/04/2006.

\section{Atividade - Diálogos com Foucault II}

Tema examinado: Problematização da sexualidade nos trabalhos de Foucault.

Estratégia adotada: percorrer as trajetórias da sua História da sexualidade buscando compreender a composição e ação do moderno dispositivo de sexualização, que marca os corpos a partir de critérios de heteronormatividade.

Percurso temático: “... a sexualidade não é um invariante”, ela tem uma história: historicidade da sexualidade; a experiência moderna: sexualização e sujeito do desejo; o lugar central da psicanálise na Scientia Sexualis e na experiência moderna; a formação e ação do moderno dispositivo de sexualização; a experiência grega da estética da existência; a experiência romana do cuidado de si; “... a sexualidade não é da ordem da natureza nem do biológico": ela se forma em jogos discursivos e práticas de normalização.

Textos discutidos: Os três volumes da História da sexualidade: A vontade de saber; $O$ uso dos prazeres; $O$ cuidado de si.

Procedimentos adotados: textos lidos por todos e discutidos de forma livre sob coordenação do professor.

Período de realização: 02/05/2006 a 26/08/2006. 


\section{Atividade - Diálogos Nietzsche \& Foucault}

Tema examinado: A inscrição de Foucault na tradição da crítica nietzschiana.

Estratégia adotada: percorrer alguns temas presentes nos pensamentos desses dois autores apontando proximidades e diferenças no tratamento dessas questões, mostrando as ligações entre esses pensamentos e buscando ainda assinalar uma leitura nietzschiana de Foucault.

Percurso temático: uma historicidade radical: Nietzsche e Foucault formando uma tradição crítica; perspectivismo e problematização da verdade; "[...] sociedade é luta, enfrentamento e sujeição"; vontade de poder, vontade de verdade, vontade de saber; a crítica ao Estado; problematização da subjetividade; genealogia da moral e genealogia da ética; domesticação, interioridade e negação de si mesmo: as reatividades cristã e moderna.

Textos discutidos: Nietzsche e a filosofia (G. Deleuze); Foucault leitor de Nietzsche (S. Marton); $1^{\text {a }}$ Conferência de $A$ verdade e as formas jurídicas (M. Foucault); A genealogia da moral e Sobre a verdade e a mentira no sentido extramoral (F. Nietzsche).

Procedimentos adotados: devido à complexidade da leitura e das articulações possíveis entre esses dois pensamentos, os textos foram lidos por todos e apresentados pelo coordenador como estratégia de geração de discussão conforme cronograma proposto.

Período de realização: 21/03/2007 a 27/06/2007.

\section{Atividade - Diálogos com Foucault III}

Tema examinado: Leituras de Vigiar e punir.

Estratégia adotada: explorar a diversidade de possibilidades de leitura tendo em conta os atravessamentos temáticos do livro Vigiar e punir, cruzando perspectivas e dando visibilidade a seus múltiplos projetos.

Percurso temático: a leitura como método e estratégia de entrada em um texto articulado; o projeto "vertical" da história do nascimento das prisões; o pano de fundo da genealogia do poder; os projetos "transversais" - porque atravessam o tema central - da genealogia das sociedades ocidentais, da genealogia do indivíduo moderno e da genealogia da psicologia.

Textos discutidos: O livro Vigiar e punir lido de perspectivas diversas.

Procedimentos adotados: alguns membros do Grupo foram encarregados de explorar cada uma das perspectivas do livro e coordenar os encontros dedicados à leitura de cada uma delas, dando visibilidade a cada projeto traçado. Essa atividade gerou um artigo produzido e encaminhado para publicação por três membros do grupo.

Período de realização: 06/08/2007 a 30/11/2007. 


\section{HUMANAS}

Atividade - Foucault e a psicanálise

Tema examinado: Diálogos e debates de Foucault com a psicanálise.

Estratégia adotada: explorar as relações de Foucault com a psicanálise, marcando sua importância e mostrando em textos diversos suas diferenças de tratamento em relação às perspectivas de Freud e de Lacan.

Percurso temático: uma cartografia das relações entre Foucault e a psicanálise; a psicanálise e o triedro dos saberes em As palavras e as coisas; o projeto de uma arqueologia da psicanálise em $A$ vontade de saber; o lugar da psicanálise em $O$ uso dos prazeres; problematização do Édipo em $A$ verdade $e$ as formas jurídicas; a questão da interpretação em Nietzsche, Freud \& Marx; confissão e hermenêutica do sujeito: problematização do sujeito e da subjetividade entre Foucault e a psicanálise.

Textos discutidos: As palavras e as coisas; História da sexualidade I e II; $2^{\mathrm{a}}$ Conferência de $A$ verdade e as formas jurídicas; Nietzsche, Freud \& Marx; Foucault e a psicanálise (E. Chaves); Foucault e a psicanálise uma arqueologia inacabada. (R. Mezan).

Procedimentos adotados: devido a uma convergência de interesses em relação ao tema que transbordou o âmbito do Grupo, a atividade foi desenvolvida como disciplina do Programa de Pós-graduação em psicologia da UFSC no semestre 2007/2, contando com a participação de vários membros do Grupo, entre outros alunos de pós-graduação.

Período de realização: 30/08/2007 a 06/12/2007.

\section{Atividade - Diálogos com Foucault IV}

Tema examinado: Matrizes discursivas da luta antimanicomial.

Estratégia adotada: a partir de um olhar arqueológico, expor os atravessamentos discursivos na luta antimanicomial, assinalando suas diferenças de posição, de objeto e de estratégias.

Percurso temático: a formação de um campo de debates críticos em torno da marcação da loucura e das violências psiquiátrica e manicomial nos anos 1960/70; problematização da loucura como exclusão por Foucault; a crítica antipsiquiátrica de Cooper; a produção da doença mental segundo Szasz; a crítica antimanicomial de Basaglia; uma radiografia das instituições totais traçada por Goffman.

Textos discutidos: História da loucura (M. Foucault); Psiquiatria e antipsiquiatria (D. Cooper); A fabricação da loucura (T. Szasz); A instituição negada (F. Basaglia); Manicômios conventos e prisões (E. Goffman). 


\section{Relato de experiência do Grupo de Estudos Michel Foucault}

K. Prado Filho, S. Martins \& R.D. de Vivar y Soler

Procedimentos adotados: distribuição dos textos para participantes encarregados da coordenação da discussão temática conforme cronograma, quando os responsáveis pelo encontro apresentaram e discutiram o material com a participação de todos.

Período de realização: 11/03/2008 a 01/07/2008.

\section{Atividade - Temas de pesquisa com referencial Michel Foucault}

Tema examinado: Variações e singularidades metodológicas envolvendo a aplicação das indicações de métodos feitas por Foucault.

Estratégia adotada: Restringir o funcionamento do Grupo a atividades de orientação, objetivando maior suporte às pesquisas de pós-graduação em andamento através do aprofundamento de discussões metodológicas.

Percurso temático: relações arqueológicas entre a criminologia e a psicologia; a implantação contemporânea de dispositivos eletrônicos de vigilância e monitoramento de prisioneiros; a prática de geoprocessamento como dispositivo de vigilância e segurança; a Estratégia de Saúde da Família problematizada como dispositivo; Urubici: turistificação e produção de uma heterotopia; autoria e transgressão em "Lavoura arcaica"; leituras transversais do estatuto do intelectual contemporâneo; problematização da subjetividade nos diálogos entre Foucault, Deleuze e Guattari; uma analítica interpretativa da velhice como dispositivo; políticas de segurança como tecnologia de governo; jogos de objetivação e subjetivação na Estratégia de Saúde da Família.

Textos discutidos: projetos de pesquisa de cada participante.

Procedimentos adotados: no ano de 2009, devido a uma convergência de interesses em torno de atividades de orientação, o Grupo restringiu-se ao núcleo dos orientandos + orientador, inclusive desdobrando a atividade em outra dedicada especificamente a questões de método. Optou-se, nesse primeiro semestre, pela realização de seminários para apresentação dos projetos de pesquisa por cada um dos orientandos do coordenador, proporcionando discussão das propostas pelos colegas de orientação, possibilitando trocas e assinalando a multiplicidade de possibilidades de aplicação metodológica.

Período de realização: 15/03/2009 a 15/07/2009.

\section{Atividade - Métodos de pesquisa a partir dos olhares de Michel Foucault}

Tema examinado: Perspectivas arqueológicas e genealógicas de análise.

Estratégia adotada: aprofundar estudos e desenvolvimentos metodológicos a partir das estratégias de análise propostas por Foucault, objetivando obter um suporte mais sólido a pesquisas realizadas a partir das suas perspectivas. 


\section{HUMANAS}

Percurso temático: o eixo metodológico saber- poder-subjetividade; arqueologia do saber e relações subjetividade $\mathrm{x}$ verdade; genealogia do poder e disciplinarização dos corpos; genealogia da ética: relações consigo mesmo e subjetivação.

Textos discutidos: A arqueologia do saber; A vontade de saber; Nietzsche, a genealogia e a história; $O$ sujeito e o poder; Introdução de $O$ uso dos prazeres.

Procedimentos adotados: essa atividade resulta do desdobramento daquela que lhe antecede, aprofundando a discussão sobre métodos entre os participantes do núcleo de orientação. Assim, optou-se nesse momento pela realização de seminários metodológicos para discussão de textos norteadores e produção coletiva de uma síntese relativa a cada método proposto por Foucault, visando publicação do material como resultado e autoria do Grupo.

Período de realização: 01/09/2009 a 30/11/2009.

\section{Outras atividades desenvolvidas pelo Grupo}

Além das atividades aqui descritas, em seus cinco anos de funcionamento o Grupo de estudos M. Foucault gerou ainda dez dissertações de mestrado, três teses de doutorado, muitas apresentações conjuntas ou não em encontros e congressos, além de vários artigos e capítulos de livros em autoria solo ou coautoria.

Apresentamos a seguir um breve resumo de cada uma dessas dissertações e teses, esclarecendo que nem todas encontram-se disponibilizadas no site do Programa de Pós-graduação em Psicologia; assim, indicamos no item "Referências" aquelas que estão disponíveis.

Ricardo Abussafy (2006) traçou uma cartografia de uma rede social quanto a práticas e efeitos de subjetivação em jogo na produção de cidadania, envolvendo uma ONG no Bairro Monte Cristo em Florianópolis, trabalho intitulado: "Subjetivações e tecnologias da cidadania: cartografias sobre uma rede social".

Gisele Mânica (2007), numa leitura arqueológica de discursos confessionais sobre anorexia postados em weblogs, fez um estudo relativo à estetização e produção de corpos anoréxicos em nossa cultura contemporânea, intitulado: "Quando se perfaz um dispositivo confessional, a palavra escrita se desvela e o corpo revela-se".

Simone Martins (2008) desenvolveu uma pesquisa relativa às "Relações arqueológicas entre discursos criminológicos e psicológicos: a legitimação de saberes e práticas", contemplando as implicações entre esses dois campos de saber em termos dos seus enunciados; buscando situar, ainda, a emergência de disciplinas nesta interface, como a psicologia jurídica, psicologia criminal e psicologia judiciária, discutindo a atualidade de suas práticas. 


\section{Relato de experiência do Grupo de Estudos Michel Foucault}

K. Prado Filho, S. Martins \& R.D. de Vivar y Soler

Janaína Geraldini (2009) realizou uma pesquisa documental relativa ao tema "O monitoramento eletrônico como dispositivo do controle no sistema prisional brasileiro", onde acompanhou propostas e experiências-piloto de implantação de dispositivos de vigilância e monitoramento eletrônico de prisioneiros no Brasil, conhecidos como "tornozeleiras eletrônicas".

Cristian Stassun (2009) desenvolveu uma análise genealógica referente à implantação de um sistema de geoprocessamento em um município catarinense, trabalho intitulado: "Geoprocessamento como prática biopolítica de governo municipal: desenho de um dispositivo", onde aponta a geotecnologia como recurso de saber e poder aplicado como prática de governo biopolítico da população e dos indivíduos.

Pablo Raimundo (2010) procedeu, de uma perspectiva arqueológica, uma leitura da questão transgressão no texto - livro e filme - "Lavoura arcaica", posta em correlação com a postura de recusa do lugar de autor observável na atitude do seu escritor, Raduan Nassar; trabalho intitulado: "Autoria e transgressão em Lavoura arcaica".

Marcela Montalvão Teti (2010) realizou uma pesquisa genealógica analisando interesses de instâncias governamentais em diferentes níveis e relações de força em movimento no processo de turistificação de um município catarinense, intitulada, "Urubici: a formação geopolítica de uma heterotopia turística".

Gissele Cristina Pinto (2010) desenvolveu um estudo genealógico relativo à temática "Biopolítica, saúde e governamentalidade: uma problematização da estratégia saúde da família a partir de breve genealogia das políticas de saúde pública no Brasil", onde analisou a Estratégia de Saúde da Família como prática biopolítica de governo da vida da população e dos indivíduos pela vigilância e promoção da sua saúde.

Rodrigo Diaz de Vivar y Soler (2011) fez uma análise histórica transversal sobre o estatuto do intelectual nas tradições críticas do marxismo e da desconstrução nietzschiana, intitulada, "Por uma vida não fascista: leituras tranversais sobre o estatuto do intelectual na contemporaneidade", colocando em foco as diferentes figuras do intelectual revolucionário, do intelectual orgânico e do intelectual específico.

Carlos Antônio Cardoso Filho (2011) desenvolveu um estudo relativo à leitura da questão da subjetividade nos diálogos possíveis entre Foucault, Deleuze e Guattari em torno do tema, intitulado, "Ceticismo e ingenuidade: a problematização da subjetividade nos pensamentos de Foucault, deleuze e Guattari".

Almir Pedro Sais (2011) defendeu tese aplicando um analítica interpretativa ao problema da velhice, dando visibilidade a um dispositivo de produção de corpos e subjetividades de idosos em nossa cultura, num trabalho intitulado: "Dispositivo de velhice: uma analítica interpretativa". 


\section{UMANAS}

Deise Maria do Nascimento (2011) defendeu tese realizando um estudo arqueológico relativo às políticas de segurança como tecnologia de governo biopolítico, intitulado: "Políticas de segurança pública: punição e técnicas de governo - um estudo arqueológico".

Ana Maria Lopes, num trabalho ainda em andamento, desenvolve pesquisa de tese analisando efeitos de objetivação e subjetivação de sujeitos da saúde, decorrentes da aplicação da Estratégia de Saúde da Família como dispositivo de vigilância, promoção de saúde e governo biopolítico da população e dos indivíduos (Trabalho com defesa prevista para dezembro de 2011).

\section{Depoimento final}

Levando em conta a perspectiva uma história crítica do presente, cabe salientar que o Grupo de Estudos Michel Foucault proporcionou ainda espaço para formulação de questões para além de horizontes estritamente acadêmicos ou intelectuais, acolhendo propostas e instrumentalizando práticas concretas de resistência e de liberdade.

Pensamos, assim, que a experiência aqui relatada possa servir como metodologia, modelo flexível ou inspiração para outras iniciativas de estudo coletivo de temáticas, autores, ou sistemas de pensamento, voltadas à produção de conhecimento, à formação de postura crítica e mesmo de protagonismo social.

\section{Referências bibliográficas}

BASAGLIA, F. A instituição negada: relato de um hospital psiquiátrico. Rio de Janeiro: Graal, 1985.

CHAVES, E. Foucault e a psicanálise. Rio de Janeiro: Forense/Universitária, 1988

COOPER, D. Psiquiatria e antipsiquiatria. São Paulo: Perspectiva, 1973.

DELEUZE, G. Nietzsche e a filosofia. Rio de Janeiro: Editora Rio, 1976.

FOUCAULT, M. Nietzsche, a genealogia e a história. In: R. MACHADO (Org.). A microfísica do poder. Pp. 15-38. Rio de Janeiro: Graal, 1984.

FOUCAULT, M. A arqueologia do saber. Rio de Janeiro: Forense/Universitária, 1987.

FOUCAULT, M. As palavras e as coisas. São Paulo: Martins Fontes, 1987. 


\section{Relato de experiência do Grupo de Estudos Michel Foucault \\ K. Prado Filho, S. Martins \& R.D. de Vivar y Soler}

FOUCAULT, M. Nietzsche, Freud \& Marx. São Paulo: Princípio, 1987.

FOUCAULT, M. Vigiar e punir. Petrópolis: Vozes, 1987.

FOUCAULT, M. História da sexualidade I: A vontade de saber. Rio de Janeiro: Graal, 1988.

FOUCAULT, M. História da loucura. São Paulo: Perspectiva, 1989.

FOUCAULT, M. História da sexualidade III: O cuidado de si. Rio de Janeiro: Graal, 1989.

FOUCAULT, M. História da sexualidade II: O uso dos prazeres. Rio de Janeiro: Graal, 1990.

FOUCAULT, M. El orden del discurso. Buenos Aires: Tusquets, 1992.

FOUCAULT, M. La verdade y las formas jurídicas. Barcelona: Gedisa, 1992.

FOUCAULT, M. O sujeito e o poder. In: H. DREYFUS \& P. RABINOW. $M$. Foucault: uma trajetória filosófica. Pp. 231-49. Rio de Janeiro: Forense/Universitária, 1995.

FOUCAUlT, M. Eu, Pierre Rivière que degolei minha mãe, minha irmã e meu irmão. Rio de Janeiro: Graal, 2003.

GERALDINI, J. R. O monitoramento eletrônico como dispositivo de controle no sistema prisional brasileiro. Dissertação de Mestrado. Florianópolis: Programa de Pós-Graduação em Psicologia, UFSC, 2009. Documento em PDF: http://www.cfh.ufsc.br/ ppgp/Janaina\%20Geraldini.pdf.

GOFFMAN, E. Manicômios, prisões e conventos. São Paulo: Perspectiva, 1999.

MARTINS, S. Relações arqueológicas entre discursos criminológicos e psicológicos: a legitimação de saberes e práticas. Dissertação de Mestrado. Florianópolis: Programa de Pós-Graduação em Psicologia, UFSC, 2008. Documento em PDF: http://www.cfh.ufsc.br/ ppgp/Simone\%20Martins.pdf.

MARTON, S. Foucault leitor de Nietzsche. In: R.J. Ribeiro (Org.). Recordar Foucault. p. 36-45. São Paulo: Brasiliense, 1985.

MEZAN, R. Foucault e a psicanálise - uma arqueologia inacabada. In: R.J. Ribeiro (Org.). Recordar Foucault. p. 94-125. São Paulo: Brasiliense, 1985.

NIETZSCHE, F. Sobre verdade e mentira no sentido extramoral. In: F. Nietzsche. p. 29-38. São Paulo: Nova Cultural (Coleção Os Pensadores, vol. 1), 1987. 
UMANAS

NIETZSCHE, F. A genealogia da moral. São Paulo: Brasiliense, 1988.

PINTO, G.C. Biopolítica, Saúde e Governamentalidade: uma problematização da estratégia Saúde da Família a partir de breve genealogia das políticas de saúde pública no Brasil. Dissertação de Mestrado. Florianópolis: Programa de Pós-Graduação em Psicologia, UFSC, 2010. Documento em PDF: http:// www.cfh.ufsc.br/ ppgp/Gissele\%20Cristina\%20Pinto.pdf.

STASSUN, C.C.S. Geoprocessamento como prática biopolítica de governo municipal: desenho de um dispositivo. Dissertação de Mestrado. Florianópolis: Programa de Pós-Graduação em Psicologia, UFSC, 2009. Documento em PDF: http://www.cfh.ufsc.br/ ppgp/Cristian\%20Stassun.pdf.

TETI, M.M. Urubici: a formação geopolítica de uma heterotopia turística. Dissertação de Mestrado. Florianópolis: Programa de Pós-Graduação em Psicologia, UFSC, 2010. Documento em PDF: http://www.cfh.ufsc.br/ ppgp/ Marcela\%20Montalvao\%20Teti.pdf.

VIVAR Y SOLER, R.D. Por uma vida não fascista: leituras transversais Sobre o estatuto do intelectual na Contemporaneidade. Dissertação de Mestrado. Florianópolis: Programa de Pós-Graduação em Psicologia, UFSC, 2011. Documento em PDF: http://www.cfh.ufsc.br/ ppgp/ Rodrigo\%20Diaz\%20de\%20Vivar\%20y\%20Soler.pdf. 